\title{
NEUROPROTECTIVE POTENTIALS OF Lycopersicon Esculentum FRUIT EXTRACT ON CADMIUM-INDUCED TOXICITY IN POSTNATAL DEVELOPING CEREBELLUM OF RATS
}

\author{
Imosemi Innocent Ohiorenuan, Mustapha Olufunke Wuraola
}

Correspondence to Dr Innocent O. Imosemi, Departments of and Anatomy, College of Medicine, University of Ibadan, Ibadan, Nigeria. Phone no.: +234706 802 5958. E-mail: innosemi@yahoo.co.uk.

\begin{abstract}
The neuroprotective potemtials of Lycopersicon esculentum fruit extract on cadmium-induced oxidative stress in postnatal developing cerebellum of rats. Twenty-five pregnant Wistar rats $(110-200 \mathrm{~g})$ were divided into five groups $(\mathrm{n}=5)$ and used for the experiment. Group I served as control and received water, Group II received $0.5 \mathrm{mg} / \mathrm{kg}$ of Cadmium only, Group III received $50 \mathrm{mg} / \mathrm{kg}$ aqueous extract of Lycopersicon esculentum only, Group IV received $0.5 \mathrm{mg} / \mathrm{kg}$ body weight of cadmium $+50 \mathrm{mg} / \mathrm{kg}$ aqueous extract of Lycopersicon esculentum and Group V received $0.5 \mathrm{mg} / \mathrm{kg}$ of cadmium $+200 \mathrm{mg} / \mathrm{kg}$ of vitamin C, orally from the first day of gestation to postnatal day 21. Lycopersicon esculentum was administered one hour before the administration of cadmium. Neurobehavioural tests was done on the pups of day 21. Then, pups of day $1,7,14,21$, and 28 were weighed, sacrificed and their brains dissected out, weighed with the cerebellum preserved for biochemical and histomorphological evaluations. Data were analysed using ANOVA at $p<0.05$. Cadmium-treated rats showed significant decreased in body and brain weight, decreased time spent on the forelimb grip, increased negative geotaxis, increased lipid peroxidation (LPO), and decreased glutathione (GSH), catalase (CAT), superoxide dismutase (SOD) and glutathione peroxidase (GPx) in the developing cerebellum. Histologically, there was persistent external granular layer $(E G L)$, reduced molecular layer $(\mathrm{ML})$ thickness and increased astrocytes population in the cerebellar cortex of cadmium-treated day 21pups. Lycopersicon esculentum extract and vitamin $\mathrm{C}$ reversed the behavioural and morphological alterations induced by cadmium toxicity. Cadmium-induced oxidative stress, behavioural deficit and morphological alterations in the postnatal developing cerebellum of rat was ameliorated by Lycopersicon esculentum fruit extracts as such may be a potential neuroprotective agent.

Key words: Cadmium - oxidative stress - Lycopersicon esculentum - Neurobehaviour - Developing cerebellar cortex
\end{abstract}

\section{INTRODUCTION}

Cadmium (Cd) is a silvery-white, soft, ductile chemical metal with atomic number 48 and belonging to the group 12 element in d block and period 5. Commercially, Cadmium is used in television screens, lasers, batteries, paint pigments, cosmetics, and in galvanizing steel, as a barrier in nuclear fission, and was used with zinc to weld seals in lead water pipes prior to the 1960s (Patra et al.,2011; Bernhoft, 2013; Olaolu, 2018). Cadmium is considered a toxic metal and is hazardous to both human and wildlife, inducing tissue injury through creating oxidative stress (Matthew et al., 2015). Cadmium present in the atmosphere, water, or food when exposed to human in low concentration cause serious health problems and probably death. Sources of cadmium human exposures are fossil fuels, iron and steel production, cement nonferrous metals production, waste incineration, smoking and fertilizers. Plants take up cadmium from the soil and form the major source of cadmium intake in non-smoking, non-occupationally exposed populations (Inaba et al., 2005; Matthew et al., 
2015; Olaolu, 2018). Exposure to cadmium severely affects the function of the nervous system with symptoms including, headache, vertigo, olfactory dysfunction, Parkinsonian-like symptoms, slowing of vasomotor functioning, peripheral neuropathy, decreased equilibrium, decreased ability to concentrate, and learning disabilities (Swan, 2008). Cadmium readily crosses the blood-placental barrier and is excreted in the breast milk during lactation (Wang and Du, 2013). Accumulation of cadmium in the developing newborn and young brain tissues due to the not fully developed bloodbrain barrier leads to neuronal and glial cell damage, cellular dysfunction and cerebral edema (Wang and Du, 2013). Oxidative stress has been implicated in cadmium toxicity with the central nervous system highly susceptible producing neurological disturbances and changes in the normal neurochemistry of the brain (Karoui-Kharrat, et al., 2017). The ability of cadmium to induce oxidative stress in brain cells has been reported as the induction of Reactive Oxygen Species (ROS), following the interaction of cadmium with mitochondrial sites, leading to the breakdown of the mitochondrial potentials, a consequent reduction of intracellular glutathione levels (Karoui-Kharrat, et al., 2017). Cadmium enhances the production of free radicals in the brain and interferes with the antioxidant defense system which in turn leads to cadmium-induced alterations in the structural integrity of lipids and secondarily affects the membrane bound enzymes (Prabu et al., 2011). Exposure of the rat cerebellar granule neurons to increasing doses of cadmium affected the antioxidant enzymes of the cerebellum, resulting in neuronal death (Karoui-Kharrat et al., 2017).

The effects of fruits in the natural process of life cannot be over emphasized and Lycopersicon esculentum is one of such fruits (Campbell et al., 2004; Rigano et al., 2015; Uchendu et al., 2018). Lycopersicon esculentum ( $L$. esculentum) also known as tomato is a berry fruit from the nightshade family, Solanaceae. It contains phytochemicals which possess antioxidant, antibacterial, antifungal, antiviral and anticarcinogenic properties.

Studies have shown that antioxidant-rich foods or food products have potential bioactive substances that exhibit protective properties. Lycopersicon esculentum contain a substantial quantity of lycopene, a carotenoid pigment produced by vegetables and fruits and principally responsible for the deep red colour of ripe tomatoes (Uchendu et al., 2018). The hepatoprotective, nephroprotective, anticancer and antidiabetic activities of $L$. esculentum extract have been documented (Jinyao et al., 2013; Jenab et al., 2005; Banihani, 2018; Uchendu et al., 2018). However, there is dearth of information on the neuroprotective effects of L. esculentum fruit extract on cadmium-induced oxidative stress in postnatal developing cerebellum of rats, hence this study.

\section{MATERIALS AND METHODS}

Fresh fruits of Lycopersicon esculentum (tomato) were obtained from Bodija market in Ibadan, Oyo State, Nigeria in the month of August, 2018 and authenticated at the Forestry Research Institute of Nigeria (FRIN), Ibadan with a Forestry Harberium Identification (FHI) number 112308. The fruits were washed in distilled water and weighed, after which was chopped into pieces, put inside a muscilline cloth and squeezed to bring out water (liquid part of the sample). The liquid samples were later concentrated on the rotary evaporator to form gel, which was then air-dried and weighed. The weight of the fresh tomato fruit was $590 \mathrm{~g}$ and the final weight of the extract was $27.49 \mathrm{~g}$.

Twenty-five (25) healthy female Wistar rats weighing between 110 and $200 \mathrm{~g}$ were purchased from the physiology Department of University of Ibadan; they were housed in well ventilated plastic cages in the animal house of the department of veterinary physiology and biochemistry, University of Ibadan, Nigeria with a 12-hour light/dark cycle. The rats were acclimatized for two weeks and then divided into five groups of five rats per each. They were fed 
rat chow and drinking water ad libitum. Beddings was changed every three days to maintain a hygienic environment. All the female animals were introduced to healthy mature males for mating. Pregnancy was confirmed by the presence of vaginal plug and smear and taken as the first day of gestation. The pregnant rats were then kept in partitioned cages. All animals received humane care according to criteria outlined in the Guide for the Care and Use of Laboratory Animals (prepared by the National Academy of Science and published by the National Institutes of Health).

\section{Grouping and treatment of animals}

Group 1: Received clean tap water.

Group 2: $\quad$ Received cadmium as cadmium chloride, $0.5 \mathrm{mg} / \mathrm{kg}$ of cadmium chloride daily

(Jacquillet et al., 2007).

Group 3: $\quad$ Received aqueous extract of Lycopersicon esculentum ( $L$. esculentum), $50 \mathrm{mg} / \mathrm{kg}$ per

body weight daily (Owoeye and Farombi, 2015).

Group 4: $\quad$ Received cadmium and aqueous extract of $L$. esculentum, $0.5 \mathrm{mg} / \mathrm{kg}$ of cadmium chloride and $50 \mathrm{mg} / \mathrm{kg}$ per body weight daily (Jacquillet, et al., 2007; Owoeye and

Farombi, 2015).

Group 5: Received Cadmium and Vitamin C, $0.5 \mathrm{mg} / \mathrm{kg}$ of cadmium chloride and $200 \mathrm{mg} / \mathrm{kg}$ of vitamin C (Jacquillet, et al., 2007; Imosemi et al., 2010; Uchendu, 2018)

The doses administered were calculated using the average weight of the animals in each group. Administration of intervention was orally done using oral cannula (modified syringes) from day 1 of gestation through day 21 after delivery. Extracts of $L$. esculentum and vitamin $C$ was administered one hour before administration of cadmium.

Ten grams $(10 \mathrm{~g})$ of cadmium chloride $\left(\mathrm{Cdcl}_{2}\right)$ was purchased from a chemical retail store in Ibadan, Nigeria. For the $0.5 \mathrm{mg} / \mathrm{kg}$ cadmium group, $\mathrm{CdCl}_{2}$ was dissolved in $5 \mathrm{ml}$ of tap water to a concentration of $2.5 \mathrm{mg} / \mathrm{ml}$, and then $1 \mathrm{ml}$ of
$\mathrm{CdCl}_{2}$ solution was administered to the animals by using an oral cannula daily throughout gestation period till the postnatal day 21 of birthed pups. For animals in groups IV and $\mathrm{V}$ (cadmium and Lycopersicon esculentum; cadmium and vitamin $\mathrm{C}$ ), $\mathrm{CdCl}_{2}$ was dissolved in $2.5 \mathrm{ml}$ of tap water to a concentration of 2.5 $\mathrm{mg} / \mathrm{ml}$, and $0.5 \mathrm{ml}$ administered to them by using an oral cannula daily throughout gestation period till the postnatal day 21 of birthed pups (Jacquillet, et al., 2007).

Standard vitamin C was purchased from Kunle Ara pharmacy, University College Hospital road, Ibadan, Oyo State. Ten (10) tablets of $100 \mathrm{mg}$ each (i.e. $1000 \mathrm{mg}$ ) was dissolved in $2.5 \mathrm{ml}$ of tap water to a concentration of $2.5 \mathrm{mg} / \mathrm{ml}$ and then $0.5 \mathrm{ml}(200 \mathrm{mg})$ was administered to the animals in group $\mathrm{V}($ cadmium + Vitamin $\mathrm{C})$ by using an oral cannula daily throughout gestation period till the postnatal day 21 of birthed pups (Imosemi et al., 2010; Uchendu, 2018).

After birth, pups from each group were randomly selected and weighed on days $1,7,14,21$ and 28 , and neurobehavioural tests conducted on 21 pups. The pups of day $1,7,14,21$ and 28 were sacrificed by quick cervical dislocation and the brains dissected out and weighed. Some of the cerebella were preserved and homogenized for oxidative stress biomarkers, while others were fixed in $10 \%$ formol-saline for histological and immunohistochemical studies. The following parameters were evaluated;

The body and brain weight of the pups of days $1,7,14,21$ and 28 was recorded using a digital weighing balance.

On day 21 for each group, pups were made to perform two neurobehavioural tests- forelimb grip strength and negative geotaxis. The time spent in achieving these two tests were recorded using a stopwatch. The forelimb grip strength test was done to assess muscular tone and strength, while the negative geotaxis test assessed equilibrium/ balance of the rats 
according to the methods of Owoeye and Farombi, (2015).

The cerebella of day 21 pups from each group was homogenized in ice cold phosphate buffer at $\mathrm{pH} 7.4$ and centrifuged at a temperature of $4^{\circ} \mathrm{C}$ at $1500 \mathrm{rmp}$ for 10 minutes. The supernatant collected from the centrifugation was used for all oxidative stress and antioxidant markers using spectrophotometer.

The following biochemical markers were assayed for; lipid peroxidation (LPO) by measuring the formation of thiobarbituric acid reactive substances (TBARS) present in the test sample according to the method of Varshney and Kale (1990), reduced glutathione (GSH) by the method of Beutler et al., (1963), Catalase (CAT) activity was determined according to the method of Claiborne (1985), activity of superoxide dismutase (SOD) was determined by the method of Misra and Fridovich (1972) and glutathione peroxidase (GPX) activity by the method of Rotruck et al. (1973).

Cerebellar tissues from the pups of all groups were fixed in $10 \%$ formo-saline, processed employing routine paraffin embedding and stained with Haematoxylin and Eosin for histomorphological evaluation. The slides were examined and evaluated under a 500-pixel Leica digital binocular microscope and the following were evaluated in the cerebellar cortex; thickness of the external granular layer (EGL) and molecular layer (ML), and Purkinje cell density and astrocyte population using the computer software, image-j.

Cerebellar tissues were immunostained with Glial fibrillary acidic protein (GFAP) for astrocyte population (neuroglia) using the Avidin biotin immunoperoxidase method. Briefly, cut formalin-fixed paraffin sections were treated with $3 \%$ hydrogen peroxide $\left(\mathrm{H}_{2} \mathrm{O}_{2}\right)$ for $15 \mathrm{~min}$, to block endogenous peroxidase. Then, washed in phosphate buffered saline (PBS) and treated with GFAP primary antibody (GFAP, mouse monoclonal antibody 1:100 dilution, Leica Biosystems Inc. Ilinois, USA) at room temperature for $60 \mathrm{~min}$. The sections were washed in 3 changes of PBS for $5 \mathrm{~min}$ each, incubated with horseradish peroxidase (HRP) secondary biotinlated anti-mouse antibodies and washed in 3 changes of PBS for 5 mins. The sections were then incubated with diaminobenzidine (DAB) for 3 to $5 \mathrm{~min}$ and counterstained with Haematoxylin solution for 2 mins and blued briefly. Sections were dehydrated in alcohol, cleared in xylene and mounted in DPX. Images were captured from the cerebellar cortex with a 500-pixel Leica binocular microscope. Astrocyte population was counted using the software, image-j.

Data collected was further analysed as mean \pm SEM employing one-way analysis of variance (ANOVA) followed by Tukey Posthoc for multiple comparison using the GraphPad prism 6.0 at $p<0.05$.

\section{RESULTS}

In the course of the study, it was observed that the control and $L$. esculentum rats remained active throughout the experimental period, food and water intake was reduced few days before and after delivery in all groups, one pregnant rat in cadmium group had still birth and no gross deformity was seen in the control and other treated groups.
There was no significant difference in the mean body weight of the control and the treated rat pups on day 1 at $p>0.05$. The mean body weight was significantly decreased in the treated pups on days 7, 14, 21 and 28 compared with the control group at $p<0.05$. Cadmium + Lycopersicon esculentum extract group showed increased mean body weight on days 21 and 28 compared with the other treated pups (Table 1). 
Table 1: Mean body weight in grams of the control and the treated pups on days 1, 7, 14, 21 and 28

\begin{tabular}{lccccc}
\hline Group & Day 1 & Day 7 & Day 14 & Day 21 & Day 28 \\
\hline Control & $5.60 \pm 0.55$ & $10.80 \pm 0.84$ & $18.80 \pm 0.84$ & $28.20 \pm 0.79$ & $41.00 \pm 1.28$ \\
Cd & $4.80 \pm 0.84$ & $7.40 \pm 0.55 \mathrm{a}$ & $16.20 \pm 0.84$ & $18.40 \pm 1.34 \mathrm{a}$ & $20.20 \pm 0.84 \mathrm{a}$ \\
L. esculentum & $5.60 \pm 0.51$ & $7.30 \pm 0.45 \mathrm{a}$ & $13.20 \pm 1.30 \mathrm{a}$ & $18.60 \pm 1.14 \mathrm{a}$ & $29.40 \pm 0.34 \mathrm{~b}$ \\
Cd+L. esculentum & $4.80 \pm 0.84$ & $8.80 \pm 3.11$ & $16.40 \pm 0.13$ & $23.80 \pm 0.84 \mathrm{a}, \mathrm{b}$ & $29.00 \pm 0.52$ \\
Cd+Vc & $4.60 \pm 0.55$ & $7.80 \pm 0.84 \mathrm{a}$ & $11.40 \pm 0.55 \mathrm{a}, \mathrm{b}$ & $18.00 \pm 2.83 \mathrm{a}$ & $20.80 \pm 0.44 \mathrm{a}$ \\
\hline
\end{tabular}

Values $(n=5)$ are expressed as mean \pm SEM, Cd-Cadmium, L. esculentum-Lycopersicon esculentum, VcVitamin C. ap $<0.05$ vs control, $\mathrm{bp}<0.05$ vs $\mathrm{Cd}$.

There was progressive increase in the brain weight from day 1 through day 28 in all the groups. However, a significantly decreased brain weight was observed in the treated groups on days 14 and 21 pups compared with the control at $\mathrm{p}<0.05$ (Table 2).

Increased forelimb grip strength test was seen in the control and Lycopersicon esculentum-treated pups on day 21 compared with other treated groups at $p<0.05$. Vitamin $C+$ cadmium-treated group showed increased forelimb grip strength compared with the cadmium-treated pups at $\mathrm{p}<0.05$ (Figure 1).

Increased time spent for negative geotaxis was observed in the cadmium-treated pups on day 21 compared with the control and $L$. esculentum pups at $\mathrm{p}<0.05$ (Figure 2).

Table 2: Mean brain weight in grams of the control and the treated animals on days 1, 7, 14, 21 and 28 pups

\begin{tabular}{lllllc} 
Group & Day 1 & Day 7 & Day 14 & Day 21 & Day 28 \\
\hline Control & $0.41 \pm 0.01$ & $0.74 \pm 0.01$ & $1.29 \pm 0.01$ & $1.44 \pm 0.10$ & $1.53 \pm 0.03$ \\
Cd & $0.29 \pm 0.01$ & $0.57 \pm 0.01 \mathrm{a}$ & $0.80 \pm 0.01 \mathrm{a}$ & $1.18 \pm 0.13 \mathrm{a}$ & $1.46 \pm 0.01$ \\
L. esculentum & $0.39 \pm 0.19$ & $0.63 \pm 0.25$ & $0.98 \pm 0.01 \mathrm{a}$ & $1.31 \pm 0.20$ & $1.42 \pm 0.09$ \\
Cd+L. esculentum & $0.39 \pm 0.01$ & $0.70 \pm 0.01$ & $1.02 \pm 0.01 \mathrm{a}$ & $1.33 \pm 0.14$ & $1.38 \pm 0.02$ \\
Cd+Vc & $0.31 \pm 0.01$ & $0.60 \pm 0.01$ & $0.96 \pm 0.01 \mathrm{a}$ & $1.23 \pm 0.19 \mathrm{a}$ & $1.38 \pm 0.04$ \\
\hline
\end{tabular}

Values $(n=5)$ are expressed as mean \pm SEM, Cd-Cadmium, L. esculentum-Lycopersicon esculentum and Vc-Vitamin C, ap $<0.05$ vs control. 
Forelimb grip test day 21 pups

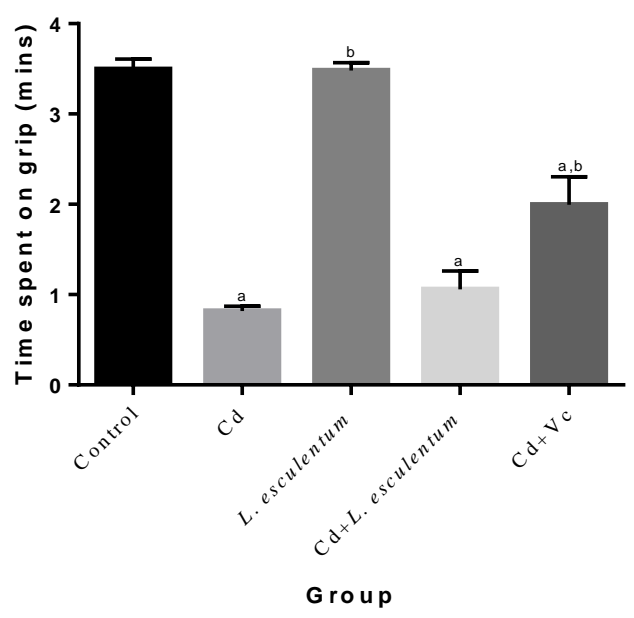

Figure 1: Forelimb grip strength test of day 21 pups. Values $(n=8)$ are expressed as mean $\pm S E M$, Cd-Cadmium, L. esculentum-Lycopersicon esculentum and Vc-Vitamin $\mathrm{C}_{\text {, ap }}<0.05$ vs control, $\mathrm{bp}<0.05$ vs $\mathrm{Cd}$.

Increased lipid peroxidation and decreased glutathione levels, superoxide dismutase and glutathione peroxidase activities was observed in the cadmium-treated pups on day 21 compared with the control and $L$. esculentum group at $\mathrm{p}<0.05$. Catalase, SOD and GPx activities was significantly decreased in the treated groups compared with the control pups at $p<0.05$ (Table 3).

Histologically, the Cerebellar cortex of day 28 pups showed normal folia and the presence of

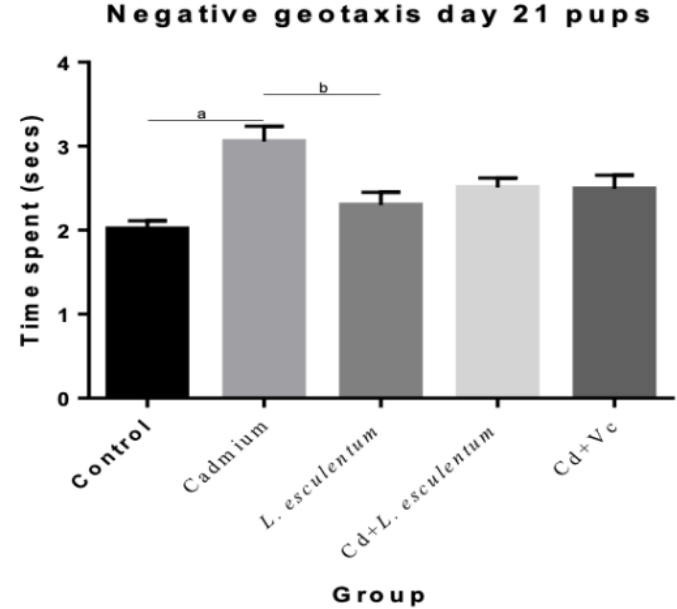

Figure 2: Negative geotaxis of pups on day 21. Values $(\mathrm{n}=8)$ are expressed as mean \pm SEM, CdCadmium, L. esculentum-Lycopersicon esculentum and Vc-Vitamin $\mathrm{C}$, ap $<0.05$ vs control, bp $<0.05$ vs $\mathrm{Cd}$.

three cell layer (molecular, Purkinje and granule cell layers) in the control and treated groups. However, in the cadmium-treated group, the Purkinje cell layer contained few necrotic and chromatolyzed cells (white arrow), while some Purkinje cells in the cadmium+Lycopersicon esculentum and cadmium+vitamin C-treated pups exhibited hyperchromatism (black arrow) (Figure 3).

Table 3: Results of oxidative stress biomarkers of day 21 pups

\begin{tabular}{lccccc}
\hline Group & $\begin{array}{c}\text { LPO } \\
\boldsymbol{\mu m o l} / \mathbf{m g} \\
\text { tissue }\end{array}$ & $\begin{array}{c}\text { GSH } \\
\boldsymbol{\mu g} / \mathbf{m g} \\
\text { tissue }\end{array}$ & $\begin{array}{c}\text { CAT } \\
\text { Unit/mg } \\
\text { tissue }\end{array}$ & $\begin{array}{c}\text { SOD } \\
\text { Unit/mg } \\
\text { tissue }\end{array}$ & $\begin{array}{c}\text { GPx } \\
\text { tissue }\end{array}$ \\
\hline Control & $0.15 \pm 0.04$ & $0.54 \pm 0.06$ & $1.15 \pm 0.13$ & $0.92 \pm 0.04$ & $1.14 \pm 0.02$ \\
Cd & $0.43 \pm 0.06 \mathrm{a}$ & $0.35 \pm 0.05 \mathrm{a}$ & $0.26 \pm 0.03 \mathrm{a}$ & $0.43 \pm 0.04 \mathrm{a}$ & $0.63 \pm 0.08 \mathrm{a}$ \\
L.esculentum & $0.13 \pm 0.05 \mathrm{~b}$ & $0.70 \pm 0.08 \mathrm{~b}$ & $0.72 \pm 0.10 \mathrm{a}, \mathrm{b}$ & $1.07 \pm 0.15 \mathrm{~b}$ & $1.11 \pm 0.07 \mathrm{~b}$ \\
Cd+L.esculentum & $0.19 \pm 0.03 \mathrm{~b}$ & $0.40 \pm 0.05$ & $0.36 \pm 0.05 \mathrm{a}$ & $0.64 \pm 0.09 \mathrm{a}$ & $0.76 \pm 0.09 \mathrm{a}$ \\
Cd+Vc & $0.18 \pm 0.04 \mathrm{~b}$ & $0.41 \pm 0.08$ & $0.47 \pm 0.06 \mathrm{a}$ & $0.67 \pm 0.07 \mathrm{a}, \mathrm{b}$ & $0.97 \pm 0.06 \mathrm{a}, \mathrm{b}$ \\
\hline
\end{tabular}

Values $(\mathrm{n}=5)$ are expressed as mean \pm SEM, Cd-Cadmium, L. esculentum-Lycopersicon esculentum, Vc-Vitamin C, CAT-Catalase, SOD-Superoxide dismutase, GSH-reduced Glutathione, LPO-Lipid Peroxidation and GPx-Glutathione Peroxidase, ap $<0.05$ vs control, $\mathrm{bp}<0.05$ vs Cd. 
Anatomy Journal of Africa. 2020. Vol 9 (2): 1835 -1847.
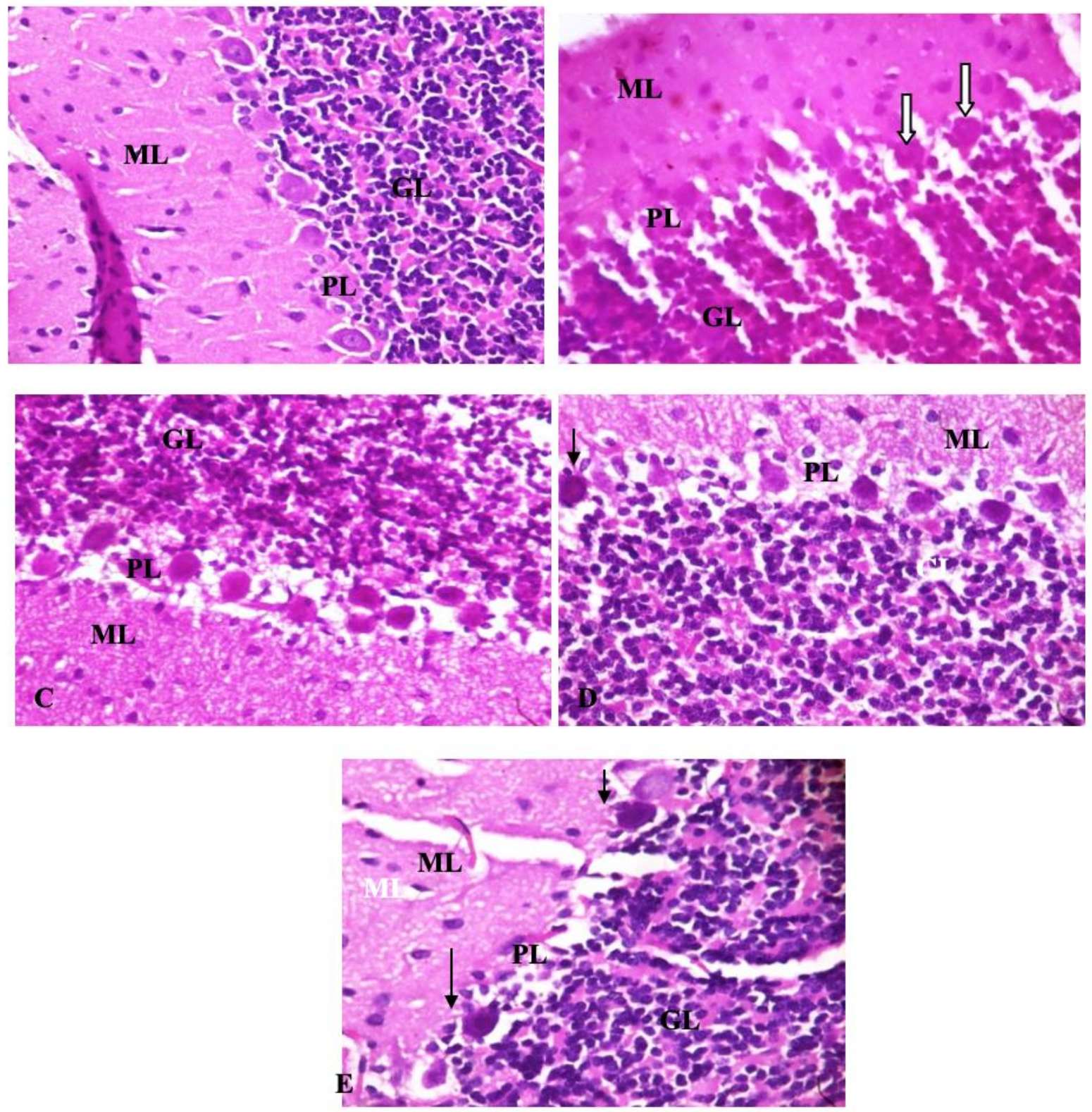

Figure 3: Photomicrographs of the cerebellum on day 28. H\&E X400 (A) Control, (B) Cadmium with some necrotic and chromatolysed (white arrow) Purkinje cells, (C) Lycopersicon esculentum, (D) Cadmium+Lycopersicon esculentum with hyperchromatolysed (black arrow) Purkinje cells (E) Cadmium+Vitamin C with hyperchromatolysed (black arrow) Purkinje cells. ML-Moleular layer, PL-Purkinje Layer, GL-Granular Layer, Pc-Purkinje cells.

Histomorphometric evaluation

External Granular layer of the cerebellar cortex on day 21 pups

The External granular layer (EGL) of the cerebellar cortex was not present in control and
Lycopersicon esculentum pups on day 21compared with the 3-4 layers thick of EGL in cadmium group, 1-2 layer thick EGL in Lycopersicon esculentum group, 2-3 layers thick $\mathrm{EGL}$ in Cadmium+Lycopersicon esculentum 
group and 2-3 layers thick EGL in Cadmium+Vitamin C group (Figure 4).

\section{Thickness of the Molecular layer of the cerebellar cortex on day 28 pups}

A decreased molecular layer thickness of the cerebellar cortex was seen in the cadmiumtreated pups on day 28 compared with the control pups at $p<0.05$. There was no significant difference in the molecular layer thickness between the control and other treated groups at $p>0.05$ (Figures 3 and 5).

\section{Cerebellar astrocyte count of day 28 pups}

Using the glial fibrillary acidic protein (GFAP) immunostain of the cerebellar cortex day 21pups, the astrocyte population was significantly increased in cadmium and cadmium+vitamin $C$ pups compared with the control pups at $p<0.05$ (Figures 6 and 7 ).
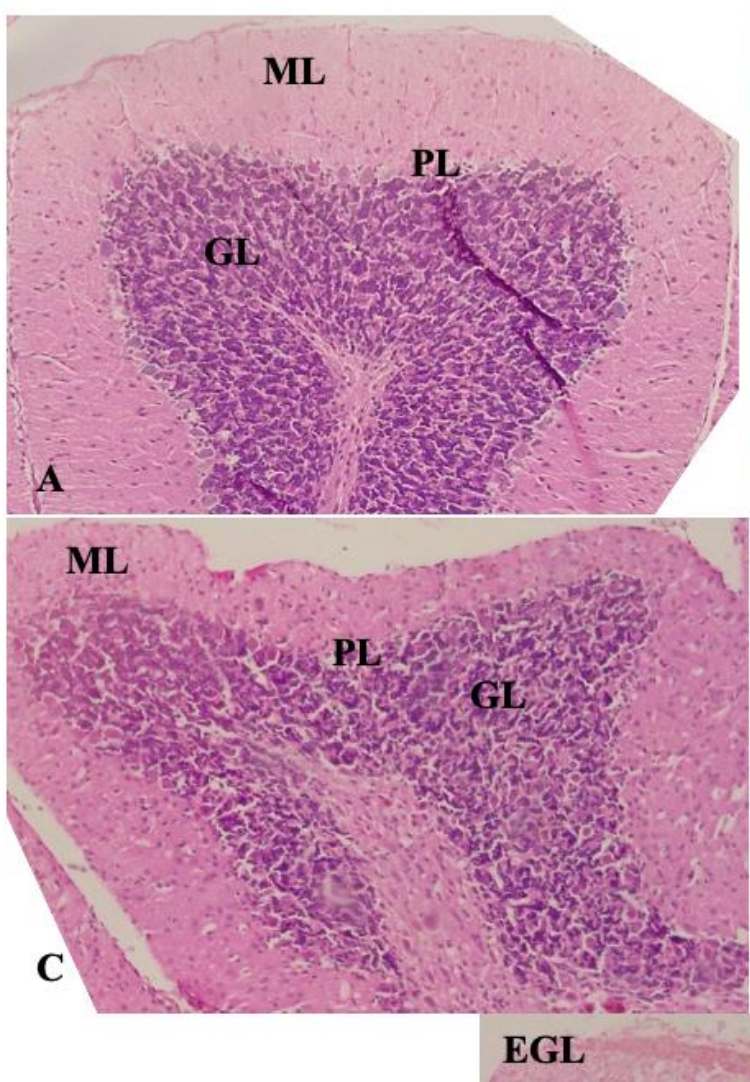
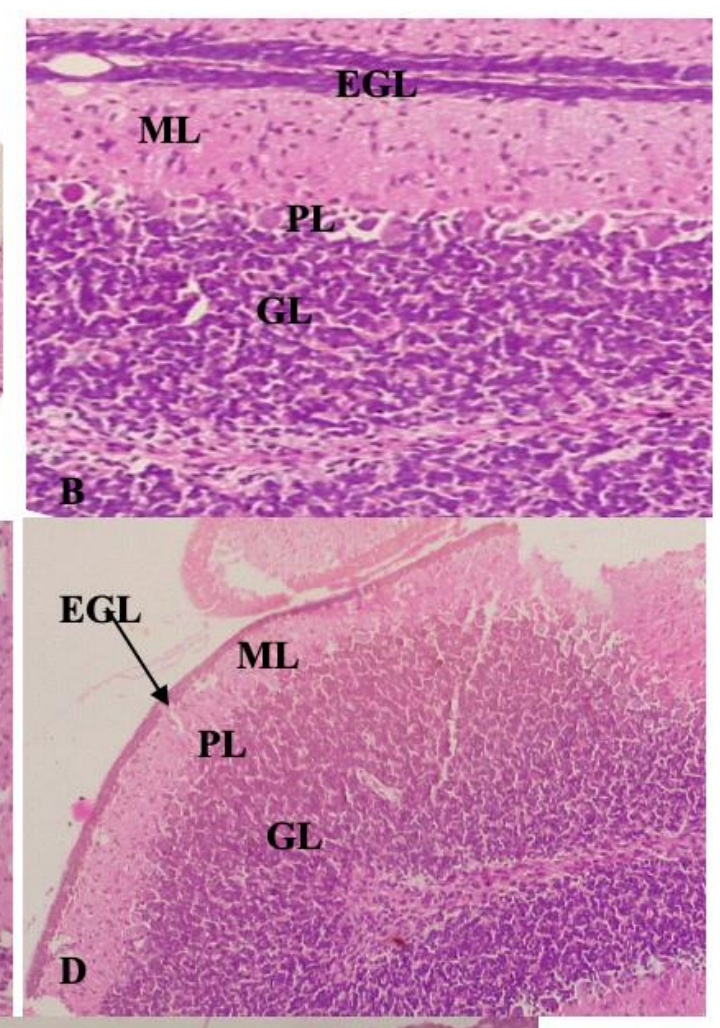

$\mathbf{E}$

ML

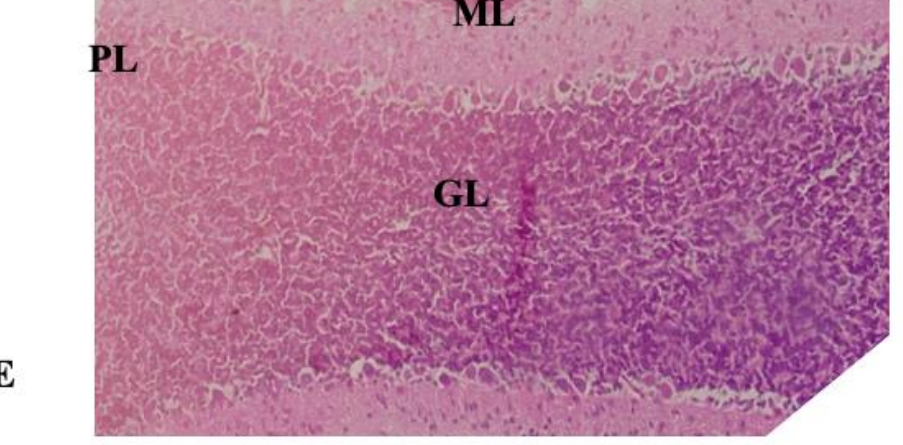

Figure 4: Photomicrographs of the cerebellar cortex of day 21 pups H\&E X100 (A). Control, disappeared EGL, (B) Cadmium, 3-4 layers thick EGL (C) Lycopersicon esculentum, disappeared EGL (D) Cadmium+Lycopersicon esculentum, 2-3 layers thick EGL (E) Cadmium+Vitamin C, 2-3 layer thick EGL, EGL-External Granular Layer, ML-Molecular layer, PL- Purkinje Layer, GL-Granular Layer. 


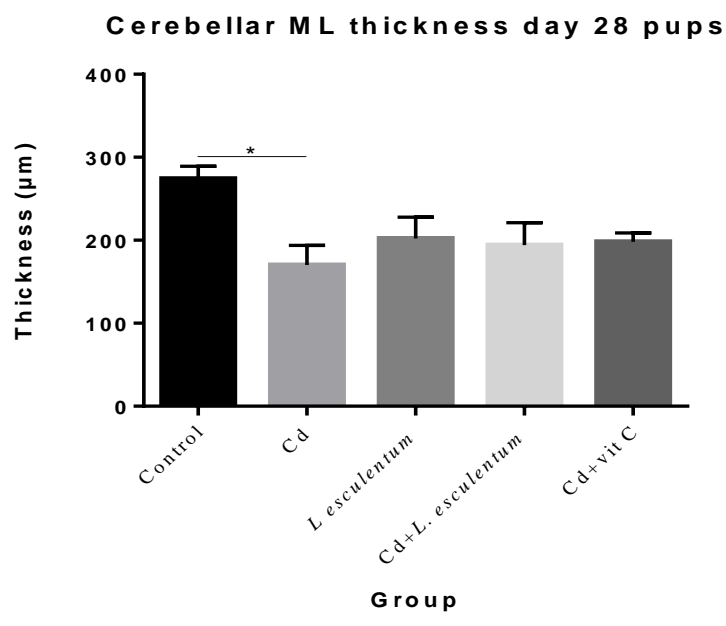

Figure 5: Thickness of the ML of the cerebellar cortex on day 28 pups. Values $(n=5)$ are expressed as mean $\pm \mathrm{SEM}$, Cd- Cadmium, L. esculentum Lycopersicon esculentum, Vc- Vitamin C, ML-Molecular Layer. ${ }^{*} p<0.05$ vs control.
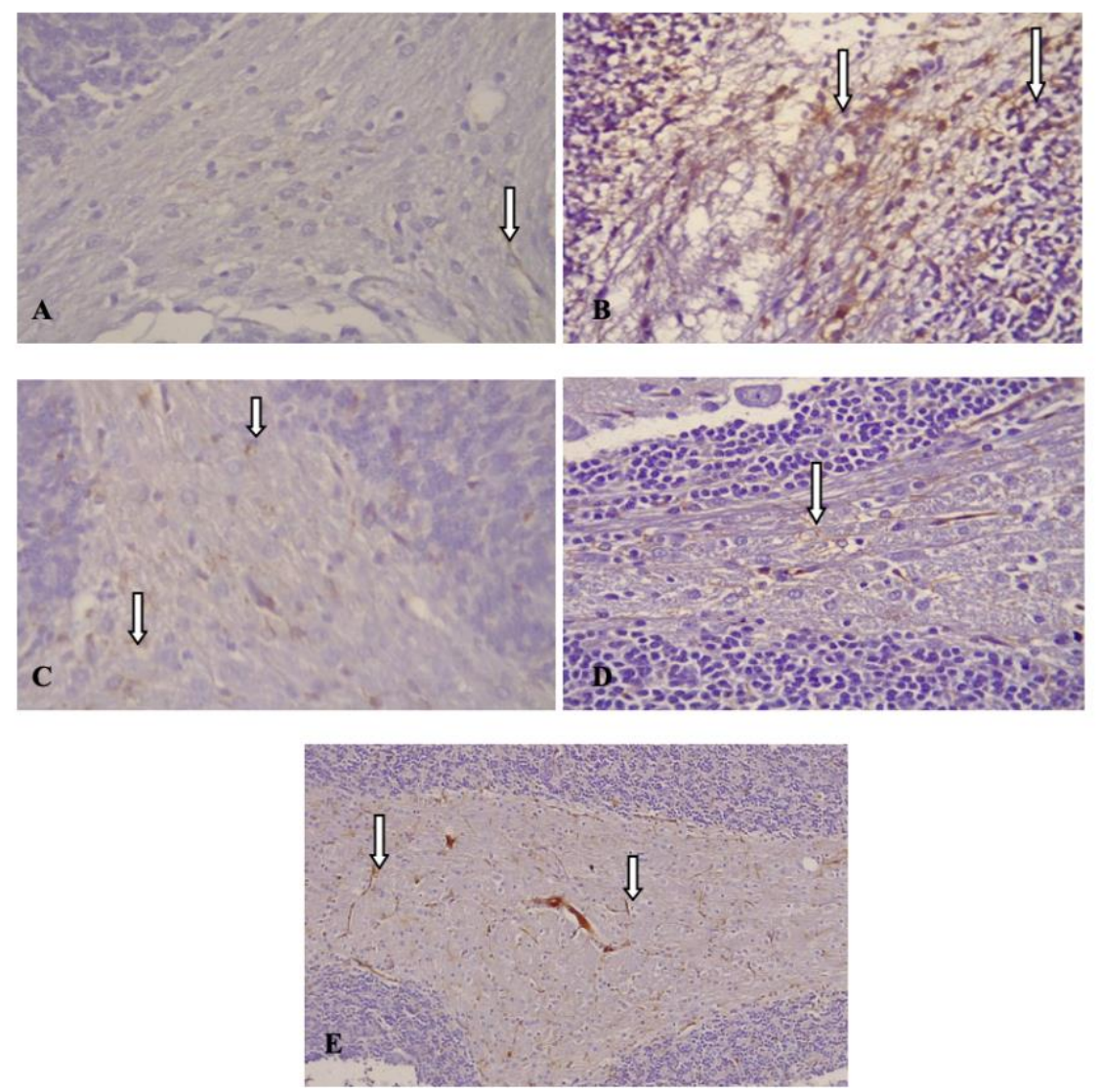

Figure 7: Photomicrographs of the cerebellar cortex showing astrocyte population on day 21, GFAP X400 (A) control, (B) cadmium group with numerous astrocytes, (C) Lycopersicon. esculentum, (D) cadmium +Lycopersicon esculentum, (E) cadmium+Vitamin C with numerous astrocytes.

Figure 6: Glial fibrillary acidic protein (GFAP) immunostain of the cerebellar cortex for astrocyte count on day 21 Postpartum. Values $(n=5)$ are expressed as mean \pm SEM, Cd- Cadmium, $L$. esculentum-Lycopersicon esculentum,Vc-Vitamin C, $*_{\mathrm{D}}<0.05$ vs control.
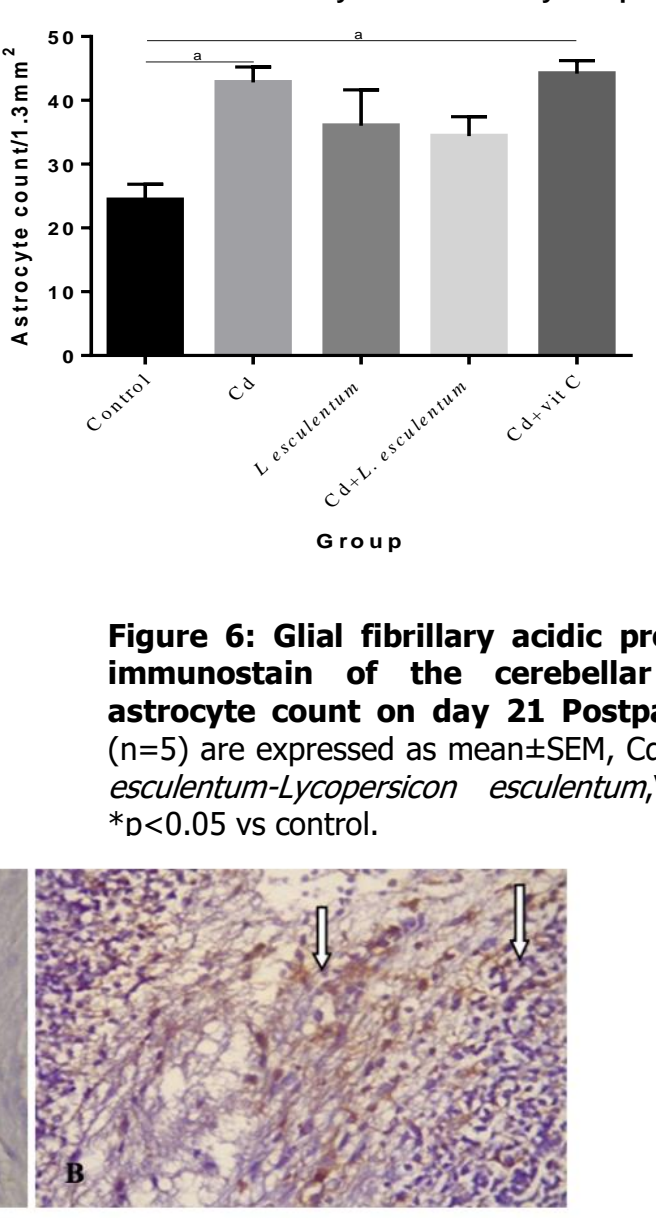

Group

\section{)
C,}




\section{DISCUSSION}

In this study, a significant decrease in body weight and brain weight was observed in the treated pups on days 7, 14, 21 and 28 compared with the control. However, Lycopersicon esculentum extracts administered to cadmiumtreated pups showed increased body weight on days 21 and 28 compared with the other treated groups. This result supports the work of Faroon et al. (2012) in which they reported significant changes in the body and brain weight of rat pups exposed to cadmium chloride. Aprioku et al. (2014) investigated the effects of prenatal cadmium exposure on fetal growth and limb development in rats and reported that cadmium significantly inhibited maternal weight gain, caused abortion, decreased fetal body weight, forelimb and hind limb bone lengths.

The forelimb grip strength test which measures muscular strength showed shorter drop off time in the cadmium, cadmium+ Lycopersicon esculentum and cadmium+vitamin C-treated pups on day 21 and an increased negative geotaxis in the cadmium-treated pups. These results corroborates the work of Hassan et al. (2008) where the pups of cadmium-treated groups showed a reduction of muscular strength and a significant increase in negative geotaxis. Cadmium has been reported to be a cumulative toxin as it accumulates chiefly in the liver and kidneys and also, in the muscle and bone. Accumulation of cadmium in these organs has been reported to induce respiratory, bone and neurological diseases including muscle weakness (Wolfgang and Jean-Marc, 2013). Negative geotaxis is considered diagnostic of vestibular and/or proprioceptive function (Mortz and Alberts, 2005). The increased negative geotaxis observed in the pups of the cadmium-treated group may be due to the affectation of the vestibular and proprioceptive function of the brain. Lycopersicon esculentum and vitamic C increased the muscular strength drop off time and decreased the negative geotaxis.

The human body has several mechanisms to counteract oxidative stress by producing antioxidants, which are either naturally produced in situ, or externally supplied through foods and/or supplements. These antioxidants act as free radical scavengers by preventing and repairing damages caused by ROS, and therefore can enhance the immune defenses and lower the risk of cancer and degenerative diseases (Imosemi et al., 2010). In the present study, cadmium induced oxidative stress as shown by significantly increased level of LPO and decreased level of SOD, CAT, GSH and GPx compared with control and Lycopersicon esculentum groups on day 21 . This result is in agreement with the report of Unsal et al. (2018) that, rats exposed to cadmium for 30 days, significantly increased tissue LPO levels and decreased GSH as well as enzymatic antioxidants, SOD, CAT, and GPx in the frontal cortex tissue when compared with the control and other treated groups. Cadmium-induced toxicity has been reported to be concerned with generation of reactive oxygen species (ROS) and exhaustion of antioxidants (Lopez et al., 2006). Previous studies have demonstrated that Lycopersicon esculentum has a potent antioxidant activity by scavenging free radicals because of the presence of including carotenoids like lycopene, phytoene, provitamin A, B-carotenoid, polyphenol, including quercetin, kaempferol and other vitamin and minerals (Kujawska et al., 2014; Owoeye and Farombi, 2015; Owoeye and Silas 2015). In this study, GSH and SOD was significantly higher in the cerebellum of pups treated with Lycopersicon esculentum extract when compared with control and cadmium-treated groups on day 21 .

Histologically, the cerebellar folia were not affected and the different layers of the cerebellar cortex appeared normal in the control and treated pups of day 28. However, the cerebellar cortex of pups exposed to cadmium showed few necrotic and chromatolysed Purkinje cells. This effect may be as a result of the oxidative stress on the developing cerebellum induced by maternal cadmium exposure.

The External granular layer is the external germinal layer that generates the outer stellate, basket, Golgi and granule cells of the cerebellar cortex. The granule cells migrate through the 
Purkinje cell layer at postnatal day 4 to form the internal granular layer (Marcelo and Fahad, 2002). In the present study, there was complete disappearance of the EGL in the control and Lycopersicon esculentum pups on day 21 compared with the 3-4 layer thick EGL seen in the cadmium-treated pups and the 1-2 layer thick EGL seen in the cadmium+Lycopersicon esculentum and cadmium+vitamin C groups. Hatten and Heintz (1995) reported that the EGL disappears on postnatal day 20 in rats. The persistent EGL seen in the cadmium-treated group may be attributed to the delayed migration of the cells of this layer as a result of the oxidative stress induced by cadmium. Marcelo and Fahad (2002) reported that exposure of neonatal rats to cadmium caused delayed cell migration and differentiation.

The Molecular layer (ML) of the cerebellar cortex, also known as the outermost layer following the complete disappearance of the EGL consists of fewer cells but mainly cell processes, dendrites and axons of neurons. Allam et al. (2011) reported that the thickness of the molecular layer depends on the number of its neuron and size of Purkinje cell arborization. In the present study, the Molecular layer of the cerebellar cortex measured on day 28 pups showed reduced thickness in the cadmiumtreated group compared with the control and Lycopersicon esculentum groups. The reason for the reduction in the ML thickness in the cadmium group is not completely clear, reports have shown that cadmium induces oxidative damage by generation of free radicals resulting in cellular death which may affect the Purkinje cell arborization in the ML (Allam et al., 2011).

Acknowledgement: We appreciate Professor E. O. Farombi for the use of his Drug Metabolism and Toxicology Research Laboratories, Department of Biochemistry, College of Medicine, University of Ibadan, Nigeria for the biochemical assays.

Declaration of interest: The authors declare that there is no conflict of interest in this study
The results from astrocyte count estimated from GFAP immunostain revealed an increase in the density of astrocytes in cadmium and cadmium+vitamin C-treated groups on day 21 compared with the control group, indicating a pathogical process known as astrogliosis. The increased astrocyte population may be due increased generation of free radicals resulting in oxidative stress Astrogliosis affects the density, morphology and function of astrocyte which is a common feature of neurodegeneration (Belozor et al., 2019). Lycopersicon esculentum decreased the density of astrocytes probably by its free radical scavenging ability and prevention of oxidative stress

From the results of this study, cadmium administered to pregnant rats, induced oxidative stress in the postnatal developing rat cerebellum as evidenced by the reduction in body weight, increased brain weight, decreased time spent on the forelimb grip, increased negative geotaxis, increased lipid peroxidation in the cerebellum and decreased glutathione, superoxide dismutase, catalase and glutathione peroxidase when compared with the control and other treated groups. Histologically, maternal cadmium caused delayed maturation and migration of the cells of the external granular layer, reduced ML thickness, few chromatolysed Purkinje cells and increased astrocyte density. Administration of aqueous extract of neurobehavioural, biochemical and morphological alteration in the developing rat cerebellum caused by cadmium toxicity, thus increasing its neuroprotective potentials. Lycopersicon esculentum ameliorated the 


\section{REFERENCES}

1. Allam A, El-Ghareeb AA, Abdul-Hamid M, Baikry A, Sabri MI. 2011. Prenatal and perinatal acrylamide disrupt the cerebellum in rat. Biochemical and morphological studies. Toxicol Ind Health. 27(4):291-306.

2. Aprioku JS, Ebenezer B, Maxwell AI. 2014. Toxicological effects of cadmium during pregnancy in Wistar albino rats. Toxicol Environ Health Sci 6 (1):16-24.

3. Banihani AS. 2018. Tomato (Solanum Lycopersicum) and type 2 diabetes. Int J Food Prop 21 (1):114-120.

4. Belozor SO, Yakovleva DO, Potapenko IV, Shuvaev AN, Smolnikova MV, Vasilev A, Pozgilenkova EA, Shuvaev AN. 2019. Extracellular S100ß Disrupt Bergman Glia Morphology and synaptic transmission in cerebellar Purkinje cells. Brain sci: 9 (4): 80. doi.org/10.3390/brainsci9040080.

5. Bernhoft RA. 2013. Cadmium Toxicity and Treatment. The Scientific World Journal. doi.org/10.1155/2013/394652.

6. Beutler E, Duron O, Kelly BM. 1963. Improved method for the demonstration of blood glutathione. J Lab Clin Med 61:882-888.

7. Campbell JK, Adams KC, Lindshield BI, Thomas WM, Boileau SK, Clinton E, Erdman JK. 2004. Tomato Phytochemicals and Prostate Cancer Risk. J Nutr 134 (3): 486S-3492S.

8. Claiborne A. 1985. Catalase activity. In: Handbook of methods for oxygen radical research (R.A. Greenwald, Ed). Boca Raton, FL, p 283-284.

9. Faroon OA, Wright S. 2012. Toxicological Profile for Cadmium. Agency for Toxic Substances and Disease Registry, USA.

10. Hatten ME, Heintz N. 1995. Mechanisms of neural patterning and specification in the developing cerebellum. Ann Rev Neurosci 18: 385-408.

11. Hassan AA, Alrasool EM, Jasem HM. 2008. Effect of cadmium on CNS function and development in rat offspring: effect of vitamin E. Iraqi J Vet Sci 22 (1): 31-37.

12. Inaba T, Kobayashi E, Suwazono Y, Uetani M, Oishi M, Nakagawa H, Nogawa K. 2005. Estimation of cumulative cadmium intake causing Itai-itai disease. Toxicol Lett 159 (2):192- 201.

13. Imosemi IO, Osinubi AA, Saalu LC. Olanguju JA 2010. Phenytoin-induced toxicity in the postnatal cerebellar development in rat: effect of Calotropis procera on selective biochemical and haematological variables. Int J Biol Chem Sci 4 (6): 2387-2396.

14. Jacquillet GO, Rubera IB, Tauc AM, Borderie MC, Namorado DM, Sierra JM, Reyes JI, Poujeol P, Cougnon M. 2007. Cadmium causes delayed effects on renal function in the offspring of cadmiumcontaminated pregnant female rats. Am J Physiol Renal Physiol. 293 (5): F1450-1460.

15. Jenab M, Ferrari P, Mazuir M, Tjonneland A, Francoise C. 2005. Variations in Lycopene blood levels and tomato consumption across European countries based on the European Prospective Investigation into Cancer and Nutrition (EPIC) study The J Nutr 135 (8): 2032S- 2036S.

16. Jinyao C, Yang S, Zhang J. 2013. Lycopene/tomato consumption and the risk of prostat cancer: a systematic review and meta-analysis of prospective studies. J Nutr Sci vitaminology 59 (3): 213222.

17. Karoui-Kharrat D, Kaddour H, Hamdi Y, Mokni M, Mohamedamri M, Mezghani S. 2017. Response of antioxidant enzymes to cadmium induced cytotoxicity in Rat cerebellar granule neurons. Open Life Sci 12: 113-119.

18. Kujawska M, Ewertowska M, Adamska T, Sadowski C, Ignatowicz E, Jodynis-Liebert J. 2014. Antioxidant effect of lycopene-enriched tomato paste on $\mathrm{N}$-nitrosodiethylamine- induced oxidative stress in rats $J$ Physiol Biochem 70 (4): 981-90. 
19. Lopez E, Arce C, Oset-Gasque MJ, Cañadas S, González MP. 2006. Cadmium induces reactive oxygen species generation and lipid peroxidation in cortical neurons in culture. Free Radical. Biol Med 40: 940-951.

20. Mathew B B, Sharma H, Rawal N. 2015. The characteristics, toxicity and effects of Cadmium. Int J Nanotech Nanosci 3: 1-9.

21. Misra HP, Fridovish I. 1972. The role of superoxide anion in the autoxidation of epinephrine and a simple assay for superoxide dismutase. The J Biol Chem 247(10):3170 3175.

22. Motz BA, Alberts JR. 2005. The validity and utility of geotaxis in young rodents. Neurotoxicol Teratol 27: 529-533.

23. Olaolu TD. 2018. Effect of cadmium on female reproduction and treatment options. Res J Obstet Gynecol 11 (1): 41-48.

24. Owoeye O, Farombi OE. 2015. Tomato pomace protects against mercuric chloride- induced neurodegeneration and motor abnormality in adult rat Int J Biol Chem. Sci: 9(3): 1142-1153. Owoeye O, Onwuka SK. 2015. Tomato pomace powder ameliorated cisplatin-induced microanatomical alterations in brain of Wistar rats Int J Biol Chem Sci 9 (1): 1-11. Patra RC, Rautray AK, Swarup D. 2011. "Oxidative stress in lead and cadmium toxicity and its amelioration" Vet Med Int Vol 2011 doi:10.4061/2011/457327

25. Rigano MM, Assunta RG, Carlo T, Barone A, Luigi F. 2015. Vitamin E Content and Composition in Tomato Fruits: beneficial Roles and Bio-Fortification. Int J mol Sci 16: 29250-29264.

26. Rotruck JT, Pope AL, Ganther HE, Swanson AB, Hafeman DG, Hoekstra WG. 1973.Selenium: biochemical role as a component of glutathione peroxidase. Sci 179 (4073): 588590.

27. Sánchez-Villagra MR, Sultan F. 2002. The cerebellum at birth in Therian mammals with special reference to rodents. Brain Behav Evol 59: 101-113.

28. Shagirtha K, Muthumani M, Prabu MS. 2011. Melatonin abrogates cadmium-Induced oxidative stress related neurotoxicity in rats Eur Rev Med pharm Sci 15: 1039-1050.

29. Uchendu IK, Agu CE, Orji OC, Nnedu EB, Arinze C, Uchenna AC, Okongwu C. 2018. Effect of Tomato (Lycopersicon Esculentum) Extract on Acetaminophen-induced acute hepatotoxicity in Albino Wistar Rat. Bio equiv Bioavailab Int J 2 (1): 000119.

30. Unsal C, Kanter M, Aktas C. 2015. Role of Quercetin in cadmium induced oxidative stress, neuronal damage and apoptosis in rats. Toxicol Ind Health 31 (12):1106-1115.

31. Vashney R, Kale RK. 1990. Effects of calmodulin antagonist Int J Radiat Biol 58: 733-743.

32. Wang B, Du Y. 2013. Cadmium and Its Neurotoxic Effects. Oxi Med Cell Long. Article ID 898034.

33. Wolfgang M, Jean-Marc M. 2013. 'The Bioinorganic chemistry of cadmium in the context of its toxicity'. Cadmium: From toxicity to essentiality. Metal ion in Life Sciences 11: 1-29. 